Article

\title{
Enhancing the Mechanical Properties of a Hot Rolled High-Strength Steel Produced by Ultra-Fast Cooling and Q\&P Process
}

\author{
Teng Wu ${ }^{1}$, Run Wu ${ }^{1, *}$, Bin Liu ${ }^{1,2}$, Wen Liang ${ }^{1,2}$ and Deqing Ke ${ }^{1}$ \\ 1 The State Key Laboratory of Refractories and Metallurgy, Wuhan University of Science and Technology, \\ Wuhan 430081, China \\ 2 Wuhan Branch of Baosteel Central Research Institute, Wuhan 430080, China \\ * Correspondence: runwu@wust.edu.cn; Tel.: +86-1398-604-3840
}

Received: 10 July 2019; Accepted: 20 August 2019; Published: 31 August 2019

\begin{abstract}
The quenching and partitioning (Q\&P) process of advanced high strength steels results in a significant enhancement in their strength and ductility. The development of controlled rolling and cooling technology provides an efficient tool for microstructural design in steels. This approach allows to control phase transformations in order to generate the desired microstructure in steel and, thus, to achieve the required properties. To refine grain structure in a Fe-Si-Mn- $\mathrm{Nb}$ steel and to generate the microstructure consisting of martensitic matrix with embedded retained austenite grains, hot rolling and pressing combined with ultrafast cooling and Q\&P process is employed. The slender martensite in hot rolled Q\&P steel improves the strength of test steel and the flake retained austenite improves the plasticity and work hardening ability through the Transformation Induced Plasticity (TRIP) effect.
\end{abstract}

Keywords: hot-rolled Q\&P steel; ultra-fast cooling; microstructure; mechanical property; work hardening

\section{Introduction}

Along with the rapid development of the automobile industry, more issues are being raised concerning the environment, energy and safety. Lightweight automobiles can reduce fuel consumption, save energy, and improve the stability of automobile operation and collision safety. As $70 \%$ to $80 \%$ of body material is steel, it must have high strength and excellent ductility. The aim is to develop the new generation of steel materials with improved strength, service life and security, and to reduce the weight of steel products as well as total consumption [1,2]. Obtaining a martensite matrix structure is an effective means to achieve this goal. Therefore, the studies on strengthening and toughening martensite steel have crucial significance in the development and application of steel materials.

In recent years, the research focus, in the field of advanced high strength steels (AHSS) for automobiles, has been on the development of third generation automobile steel with high strength and good formability. Speer et al. (2003) put forward a new process for the preparation of high strength automobile steel-Quenching and Partitioning (Q\&P) [3]. The Q\&P process consists of the following steps: (1) with a partial or full austenitizing heat treatment; (2) quenching to a temperature below the martensite start temperature $\left(M_{\mathrm{s}}\right)$ but above the martensite finish temperature $\left(M_{\mathrm{f}}\right)$; (3) an isothermal treatment at the same or higher temperature, in order to enable the diffusion of carbon from the supersaturated martensite to the residual austenite, and then quenching to room temperature [4]. The latter step stabilizes carbon-enriched retained austenite against transformation upon final quenching to room temperature. Thus, processed high strength Q\&P steels demonstrate 
the Transformation Induced Plasticity (TRIP) effect, which results in their improved ductility and toughness. Along with better formability, the martensite constituents guarantee the strength of the steel and the residual austenite improves the ductility of the steel due to transformation-induced plasticity during the deformation, which is higher than that of the first generation dual-phase (DP) steel $[5,6]$. In order to further improve the strength of steels and maintain adequate ductility, a quenching-partitioning-tempering $(\mathrm{Q}-\mathrm{P}-\mathrm{T})$ process was proposed $[7,8]$ for medium manganese steels, though it is characterized by longer processing time and higher cost.

In 2009, Speer and Matlock [9] put forward the idea of producing high-performance hot-rolled sheets directly by Q\&P process after hot rolling. Xiaodong [10] et al. took $0.21 \mathrm{C}-1.65 \mathrm{Mn}-1.67 \mathrm{Si}-0.2 \mathrm{~V}$ steel as the research subject and performed the Q\&P process after hot deformation. It was found that the tensile strength of the steel was greater than $1300 \mathrm{MPa}$, and it had better ductility and impact toughness than the traditional heat-treated samples. Similar results were also obtained by others $[5,11]$. The effectiveness of quenching and partitioning treatment after thermal-mechanical processing has been well studied and confirmed by the improvement of the performance of steel sheets.

At present, most of the hot rolled high strength steels produced and applied in the world achieve high strength through the addition of a large number of alloying elements [12], but this method not only increases the production cost but also deteriorates the weldability of the steel. The development of controlled rolling and cooling technology provides an efficient tool for microstructural design in steels. At the same time, a large number of studies have focused on the use of ultra-fast cooling (UFC) technology to obtain ideal microstructures and properties [13]. However, its role in the retention of a large number of deformed substructures and in phase transformation, relaxation, and carbon diffusion has rarely been reported [14,15]. In order to reduce alloy content, grain refinement under high temperature and high pressure is used to control the microstructures, while the composite structure of martensite and retained austenite with soft phase in hard phase is prepared by combining UFC and $\mathrm{Q} \& \mathrm{P}$ processes. The mechanism of improving mechanical properties through this process is reported in this article, thereby providing a reference for the large-scale industrial production of hot-rolled Q\&P steel.

\section{Materials and Methods}

The mechanical property of steel is largely influenced by its chemical composition. The chemical composition (wt.\%) of the investigated material is as follows: $\mathrm{C}, 0.20 ; \mathrm{Si}, 0.68 ; \mathrm{Mn}, 1.75 ; \mathrm{Nb}, 0.06$; $\mathrm{B}, 0.0025 ; \mathrm{P}, 0.0064 ; \mathrm{S}, 0.0026$; and $\mathrm{Fe}$, balance, and its corresponding phase diagram is shown in Figure 1 . The carbon content is selected at $0.2 \mathrm{wt} . \%$ to ensure that the test steel has good formability, and minimizing the content will ensure weldability. Si is mainly used to inhibit the precipitation of cementite, while $\mathrm{Mn}$ is used to increase austenitic zone, reduce austenitizing temperature, and to strengthen the solid solution $[16,17]$. In this study, a single-step method is used for partitioning treatment [18]. The temperature of the partitioning process was kept at $350^{\circ} \mathrm{C}$, which was slightly lower than the $M_{\mathrm{s}}$ point.

For sample preparation, steel was first forged into $45 \times 80 \times 120 \mathrm{~mm}$ billet, then heated to $1200{ }^{\circ} \mathrm{C}$ for $1 \mathrm{~h}$, and was subjected to controlled rolling that was carried out for five passes in a two-roll reversible hot rolling mill. The conditions for sample preparation were as follows: The reduction rate of rough rolling with three passes in recrystallization zone was $82.2 \%$; the reduction rate of finish rolling with two passes in the non-recrystallization zone was $52.5 \%$; the rolling temperature of each pass is $1120,1060,1010,930$ and $840{ }^{\circ} \mathrm{C}$ respectively, and the rolling interval time of each pass is about $10 \mathrm{~s}$. The test steel plate, of thickness $3.8 \mathrm{~mm}$, was subjected to partitioning treatment at different timings beginning with ultra-fast cooling in a salt bath to holding at $350{ }^{\circ} \mathrm{C}$ and then water quenching to room temperature to obtain Q\&P steel. Then, so as to compare with Q\&P process, the rolled steel sheet was cooled in a salt bath very quickly to air cooling relaxation at $700{ }^{\circ} \mathrm{C}$ for $6 \mathrm{~s}$ in the two-phase zone, and then water quenched to room temperature to obtain DP steel. The test process is illustrated in Figure 2. 


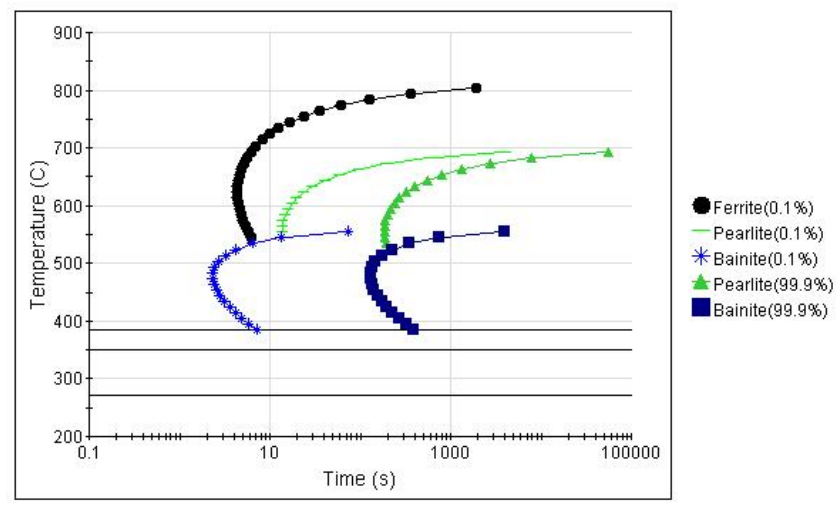

Figure 1. Time-temperature-transformation (TTT) diagram of the test steel.

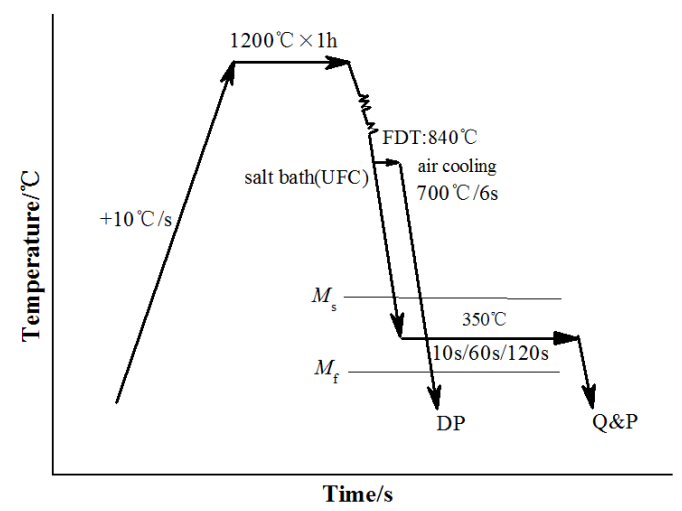

Figure 2. Process flow chart of the test steel.

At the end of the experiment, the metallographic observation surface was ground along the longitudinal section of the hot-rolled plate and the microstructure observation were prepared by $4 \%$ nitric acid-alcohol solution. The metallographic analysis was carried out with the ZEISS Axioplan 2 Universal microscope (OM, ZEISS, Oberkochen, Germany) and Nova Nano 400 scanning electron microscope (SEM, FEI, Hillsboro, OR, USA) to quantify the grain size and volume fraction of each phase in the structure. Subsequently, the sample was mechanically thinned to $0.055 \mathrm{~mm}$, and the sample for transimission electron microscopy (TEM) studies was byprepared by electropolishing using Tenupol-5 double-jet electrolyzer (Struers, Ballerup, Denmark). The TEM studies were carried out using a JEM-2100F transmission electron microscope (TEM, JEOL, Tokyo, Japan). Specimens for tensile tests were prepared with a gage length of $50 \mathrm{~mm}$ and width of $12.5 \mathrm{~mm}$ through sparkling cutting. Tensile tests were conducted using a WAW-500C testing machine (SJ, Jinan, China) with a strain rate of $10^{-4} \mathrm{~s}^{-1}$ at room temperature, measuring its mechanical properties and $n$ values. 
The amount of retained austenite was determined by a D/max-2550 X-ray diffractometer (operated at $0.1541874 \mathrm{~nm}, 30 \mathrm{~kW}, 50 \mathrm{~mA}$ ) with $\mathrm{Cu} \mathrm{K} \alpha$ radiation. The $2 \theta$ scanning angles were from 40 to $100^{\circ}$ at a scanning speed of $1.2^{\circ} / \mathrm{min}$. Since is it difficult to determine the precise amount of retained-austenite present in the steel through X-ray diffractometer (XRD), due to the development of the strong texture during rolling, which can be seen by comparing the change in the $\{111\}$ fcc nearly invisible and overerlapping $\{110\}$ bcc and $\{220\}$ fcc peak intensities, the volume fraction of retained austenite was determined semi-quantitatively through comparison with the integrated intensities of the $220 \gamma$ and $211 \alpha$ peaks according to [19]:

$$
V_{\gamma}=1.4 I_{\gamma} /\left(I_{\alpha}+1.4 I_{\gamma}\right)
$$

where $V_{\gamma}$ is the volume fraction of retained austenite, $I_{\gamma}$ and $I_{\alpha}$ are the average integrated intensities of austentite and martensite, respectively.

\section{Results and Discussion}

\subsection{Microstructure of the Test Steel}

The material was partitioned at $350^{\circ} \mathrm{C}$ for $10 \mathrm{~s}, 60 \mathrm{~s}$ and $120 \mathrm{~s}$ [7]. Figure 3 shows the microstructure of the hot rolled steel, which is composed of lath martensite and a small amount of retained austenite. The results show that a large number of deformation substructures are retained by ultra-fast cooling after controlled rolling, which promotes atom diffusion, increased nucleation rate, and forms more long martensite during cooling transformation. At the same time, carbon causes enrichment from martensite to austenite and stabilizes retained austenite content [20-22]. The residual austenite content of the specimens was measured by XRD and was found to be $9.2 \pm 1,10.6 \pm 1$ and $11.3 \pm 1 \%$, respectively, in the three processes. According to the measured results, about $10 \%$ of the untransformed austenite attains stability at room temperature due to carbon partitioning [23]. With the prolongation of partitioning time, the content of the retained austenite and the martensite lath bundle gradually increases along with the widening of the width of lath. The aforementioned phenomenon can be attributed to the diffusion and segregation of carbon atoms from the interior of supersaturated martensite lath to the martensite lath or its bundle boundary for a prolonged period of time, resulting in the enrichment of carbon atoms in the latter leading to martensite lath to corrode easily. During the partitioning process, the dislocation recovery of martensite occurs. With the disappearance of the small angle grain boundary between the slabs or the decomposition of retained austenite, when the partition time is prolonged, the merging of the martensite plate and the slab occurs, which causes the widening of the martensite slab. The test steel with ultra-fast cooling +6 s relaxation treatment (shown in Figure $3 \mathrm{~d}$ ) contained a massive amount of martensite, which combined to form flakes. The ferrite content was about $10.3 \%$ and the ferrite grain size was about $3.1 \mu \mathrm{m}$. 

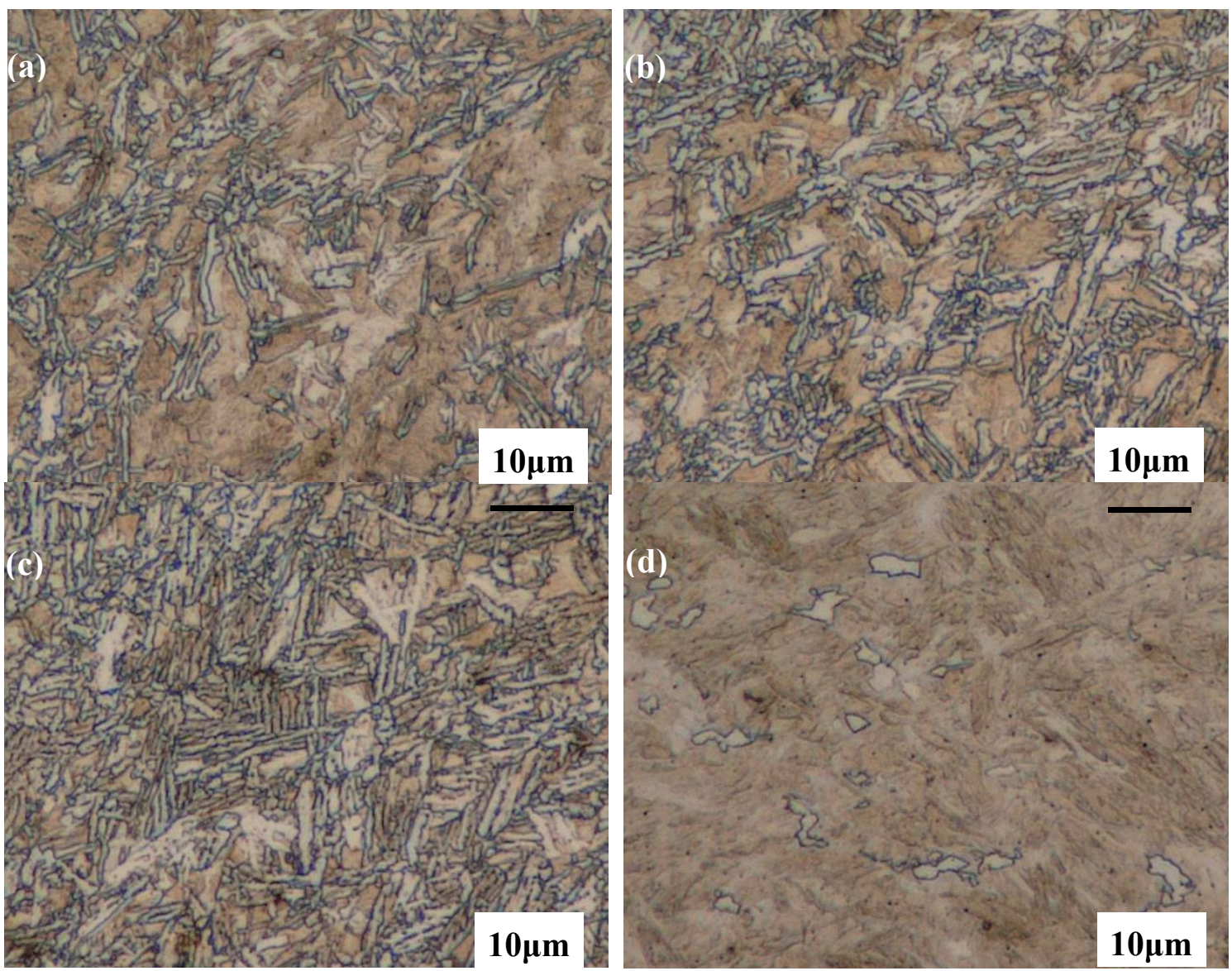

Figure 3. Microstructures of the test steel with different technology; (a) The partitioning time is $10 \mathrm{~s}$ with quenching and partitioning $(\mathrm{Q} \& \mathrm{P})$ processing; (b) The partitioning time is $60 \mathrm{~s}$ with $\mathrm{Q} \& \mathrm{P}$ processing; (c) The partitioning time is $120 \mathrm{~s}$ with Q\&P processing; (d) The relaxation time is $6 \mathrm{~s}$ with dual-phase (DP) processing.

At the same time, SEM observations were carried out on the microstructures under different processing conditions, as shown in Figure 4. Figure 4a illustrates the typical microstructure of lath martensite in which an initial austenite grain is subdivided in packages consisting of blocks. When the partitioning time was prolonged to $60 \mathrm{~s}$, the tempering transformation characteristics of the martensite structure became prominent and the martensite lath became wider and discontinuous. Visible white dotted carbide that gets distributed at the interface between lathes or at the original austenite grain boundary can be observed [24] (as shown in Figure 4b). When the partitioning time was increased to $120 \mathrm{~s}$, the boundaries between martensite laths were blurred and the $\mathrm{NbC}$ particles gradually increased in number (as shown in Figure 4c). The experimental steel treated by ultra-fast cooling with $+6 \mathrm{~s}$ relaxation (as shown in Figure 4d) showed more lath bundles and carbide particles in the martensite body and smaller particles in comparison to the experimental steel treated by the partitioning. 

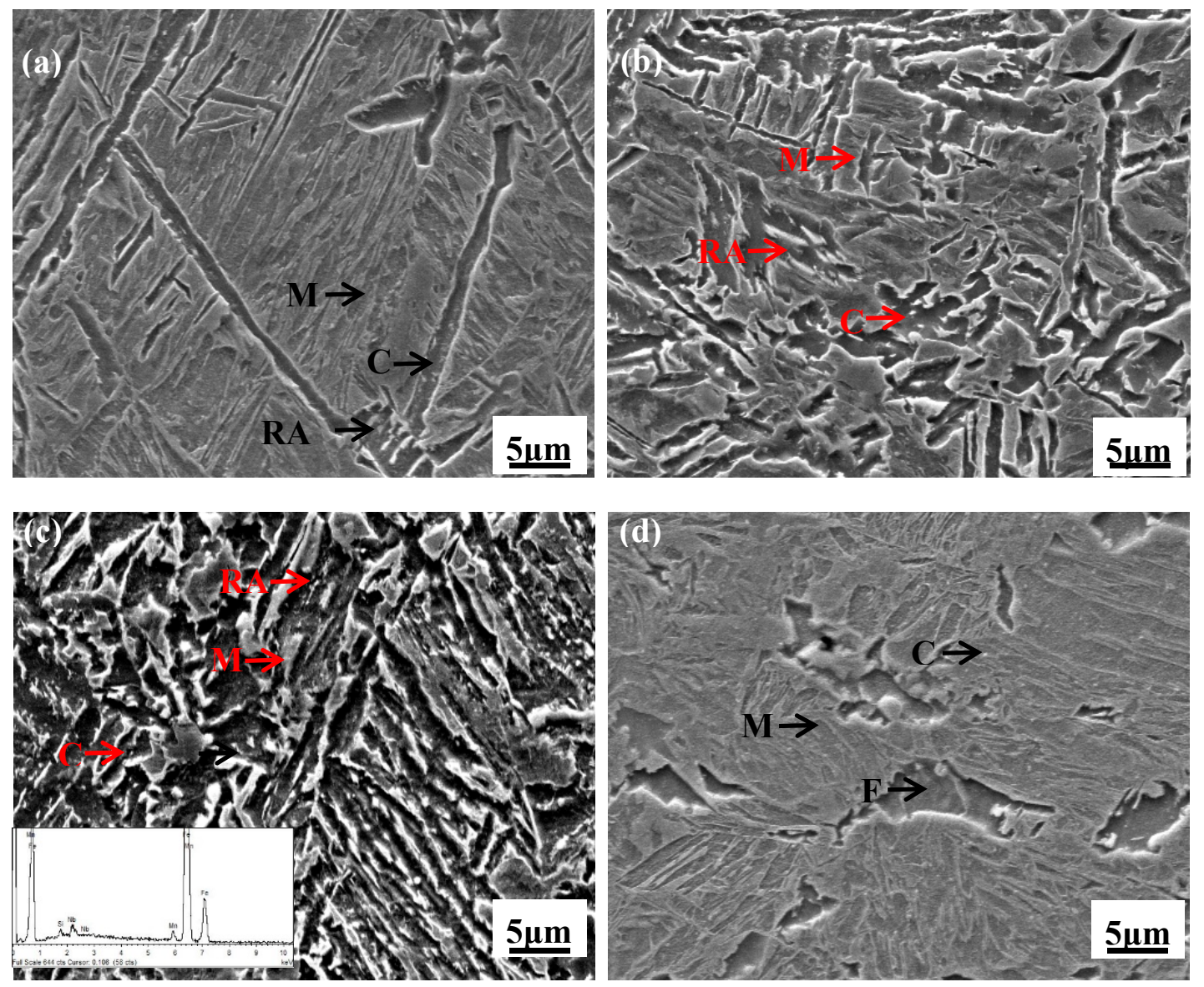

Figure 4. SEM micrographs of the test steel with different technology; (a) The partitioning time is $10 \mathrm{~s}$ with Q\&P processing; (b) The partitioning time is $60 \mathrm{~s}$ with Q\&P processing; (c) The partitioning time is $120 \mathrm{~s}$ with Q\&P processing and carbide energy spectrum; (d) The relaxation time is $6 \mathrm{~s}$ with DP processing. $M$ is martensite, $F$ is ferrite, $R A$ is retained austenite and $C$ is carbide.

\subsection{Mechanical Property}

The mechanical properties of the test steel at room temperature are shown in Table 1 . When the partition time was extended from $10 \mathrm{~s}$ to $120 \mathrm{~s}$, the tensile strength and yield strength decreased from $1201 \mathrm{MPa}$ to $1057 \mathrm{MPa}$ and $765 \mathrm{MPa}$ to $672 \mathrm{MPa}$, respectively, and the elongation increased from $21.0 \%$ to $24.0 \%$. However, DP steel attained fine ferrite after air cooling relaxation and martensite after phase transformation in the second stage of rapid cooling, which guaranteed high strength but poor ductility. Its tensile strength was $1446 \mathrm{MPa}$ and elongation was $12.0 \%$. Different heat treatment processes led to different microstructures, which correspondingly resulted in different mechanical properties. Compared with the DP steel sample, the toughness of the Q\&P steel sample was much higher and it also maintained strength. These excellent properties could be attributed to the presence of more retained austenite phases in the structure (Figure 5a) and the remarkable increase in the strength and ductility was mainly due to the refined dual-phase composite microstructure of retained austenite and martensite [10]. This refined composite structure also prevented cracking and increased toughness. 
Table 1. Mechanical properties of the test steel.

\begin{tabular}{|c|c|c|c|c|c|c|c|c|c|}
\hline Process & $\mathrm{RT}(\mathrm{s})$ & PT(s) & $\begin{array}{c}\text { RA } \\
(\text { vol } \%)\end{array}$ & $R_{\mathrm{p} 0.2}(\mathrm{MPa})$ & $R_{\mathrm{m}} / \mathrm{MPa}$ & $R_{\mathrm{p} 0.2} / R_{\mathrm{m}}$ & $A_{50}(\%)$ & $\begin{array}{c}\text { PSE } \\
(\mathrm{GPa} \%)\end{array}$ & $n$ \\
\hline$Q \& P$ & 0 & 10 & $9.2 \pm 1$ & $765 \pm 4$ & $1201 \pm 8$ & 0.637 & $21.0 \pm 1$ & 25.225 & 0.13 \\
\hline Q\&P & 0 & 60 & $10.6 \pm 1$ & $680 \pm 4$ & $1083 \pm 8$ & 0.628 & $21.5 \pm 1$ & 23.282 & 0.12 \\
\hline $\mathrm{Q} \& \mathrm{P}$ & 0 & 120 & $11.3 \pm 1$ & $666 \pm 4$ & $1056 \pm 8$ & 0.631 & $24.0 \pm 1$ & 25.359 & 0.14 \\
\hline $\mathrm{DP}$ & 6 & 0 & $<3$ & $1077 \pm 5$ & $1446 \pm 10$ & 0.745 & $12.0 \pm 1$ & 17.347 & 0.07 \\
\hline
\end{tabular}

Tensile properties are averages from three tests. RT—Relaxation time, PT—Partitioning time, RA (vol\%)—retained austenite proportion, $R_{\mathrm{p} 0.2}$-proof stress at $0.2 \%$ offset strain, $R_{\mathrm{m}}$-tensile strength, $A_{50}$-plastic component of total elongation with gage length of $50 \mathrm{~mm}, \mathrm{PSE}-R_{\mathrm{m}} \times A_{50}(\mathrm{GPa} \%), n$-work hardening value.
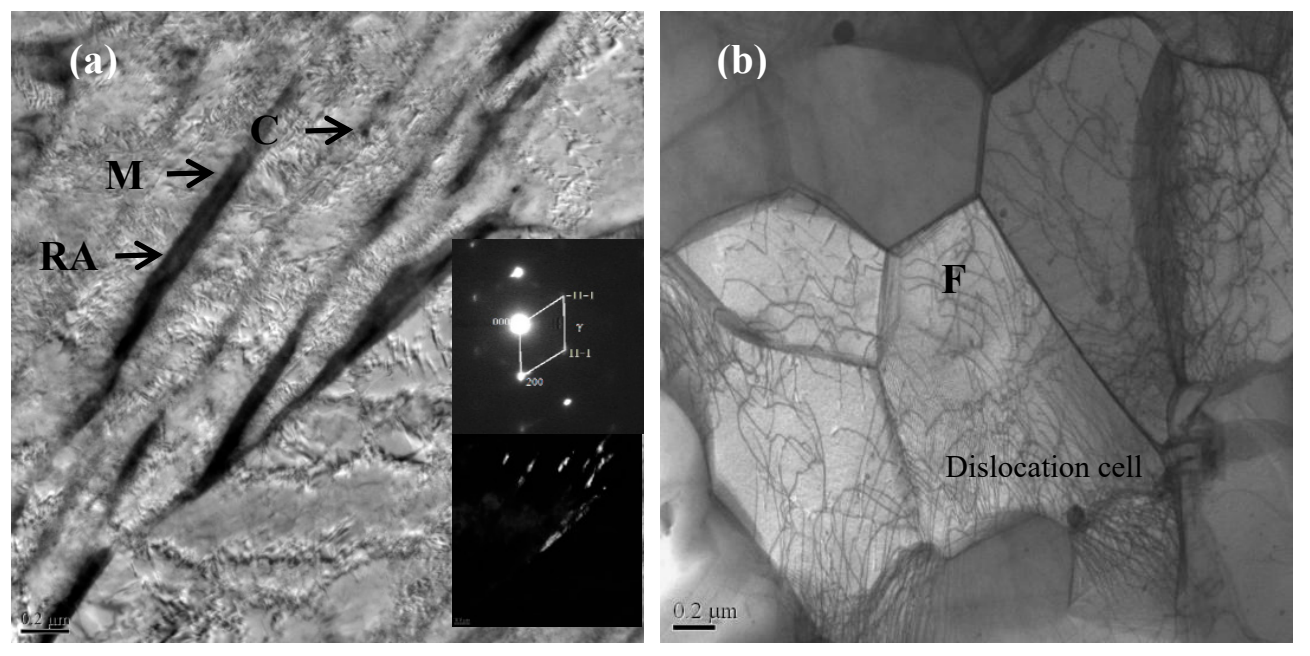

Figure 5. TEM image of the test steel with different microstructure feature; (a) The retained austenite feature when the partitioning time is $10 \mathrm{~s}$ with Q\&P processing; (b) The dislocation cell of ferrite when the relaxtion time is $6 \mathrm{~s}$ with DP processing. $M$ is martensite, $F$ is ferrite, $R A$ is retained austenite and $C$ is carbide.

Moreover, the results showed that the partitioning time also contributed to the increase in toughness. During short partitioning for $10 \mathrm{~s}$, a very small amount of carbon atoms could diffuse into retained austenite, due to a lack of time, which reduced the stability of the retained austenite. During the final quenching process, the unstable retained austenite transformed into martensite that improved the tensile strength of the steel but reduced the elongation. When the partitioning time was extended to $60 \mathrm{~s}$, the carbon atoms had enough time to diffuse into the retained austenite resulting in a significant increase in the carbon content in the retained austenite. This led to a higher retention of austenite by steel after quenching, while the martensite content decreased relatively resulting in lower tensile strength and higher elongation of the steel. However, when the partitioning time reached $120 \mathrm{~s}$, due to carbides precipitated in the retained austenite, resulting in instability. A similar phenomenon also occurred in martensite due to tempering, which caused precipitation of carbides and led to reduced carbon content, and thus, reduced the strength of the martensite. In contrast, the fine dispersed carbides between martensite slabs could have had a strengthening effect and increased the strength of steel [25-27]. The ferrite formed by relaxation in DP steel was small in size, had low elongation, and contributed to the main plastic deformation of the test steel. In the microstructure of the sample (Figure $5 b$ ), a large number of dislocation cells were seen in the ferrite body and the dislocation density became higher at the cell wall. This can be attributed to a large number of deformation substructures of austenite attained by rapid cooling after hot rolling under high pressure. The deformed substructures were retained by the precipitated ferrite and martensitic transformation occurred after the second stage of rapid cooling, resulting in the further movement of dislocations in ferrite. In summary, the DP steel, when compared with Q\&P steel, showed a higher content of martensite and carbon, which resulted in the higher yield and tensile strength. 


\subsection{Formability}

Localization of plastic deformation within an area results in local strain hardening and, in turn, in an increase in the flow stress. The latter leads to the spread of plastic slip to the surrounding non-hardened region. The strain hardening index $n$ measures the deformation hardening ability of materials during plastic deformation, where a high $n$ value indicates high uniformity of plastic deformation. Therefore, $n$ is closely related to sheet metal stamping formability and is an effective parameter to evaluate it [28]. The low yield ratio causes the material to undergo plastic deformation with larger strain when it is below the fracture stress, therefore reducing the stress concentration and improving the uniform deformation of the material. All these effects resulted in good stamping formability.

The stress-strain curves of the test steel at room temperature are shown in Figure 6. A high rate of work hardening at the initial stage of deformation was observed and there was no yield platform or upper and lower yield points on the curves implying continuous yield. This could be due to a high density of mobile dislocations in the retained austenite and the ferrite soft phase obtained by the martensite phase. The partitioning treatment and relaxation treatment of hot-rolled austenite led to the absence of carbon atoms pinning in the plastic deformation of the sample. This further prevented the occurrence of Lüders slip in steel plate processing and avoided surface wrinkles and other defects in the deep processing of steel plate. During the partitioning process, carbon atoms move to undercooled austenite, which results in a higher carbon content of the retained austenite than that of ferrite. Therefore, the yield process of Q\&P steel was gentler than that of DP steel and the yield strength was about 0.63 lower.

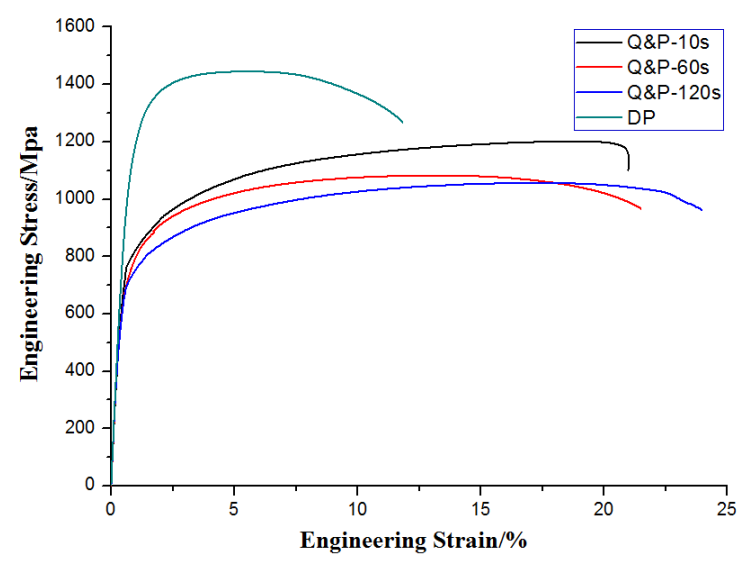

Figure 6. The room temperature tensile engineering.

Dislocation movement can be even more complex when plastic deformation occurs. Dislocation interaction, blocking of dislocation accumulation, solute atoms and second phase in materials will all hinder dislocation glide and result in the work hardening of materials. Dislocation strengthening has effects on both ductility and toughness of steel. On the one hand, the combination and the accumulation of dislocations in the barrier will promote the formation of cracks, thus reducing the plasticity of materials; on the other hand, the movement of dislocations in the plastic zone at the crack tip can alleviate the stress concentration at the crack tip, thereby improving the toughness of materials. For the test steel treated by Q\&P process, martensitic transformation occurs in retained austenite under stress, while for DP steel, the successive deformation of ferrite soft phase and martensite hard phase take place. During deformation, the transformation of the soft phase or compression produces new dislocations, which impacts the work hardening rate of the test steel.

$$
n=\frac{\varepsilon}{\sigma} \times \frac{d \sigma}{d \varepsilon}
$$

where $n$ is the strain hardening exponent; $\sigma$ and $\varepsilon$ are true stress and true strain, respectively. 
Figure 7 shows the relationship between the instantaneous strain hardening exponent $n$ and the true strain and it can be observed that at the beginning of tension, the soft phase of austenite begins to yield. With an increase in stress, the residual austenite phase will cause hardening, the main load will transfer to the martensite phase, and plastic deformation will begin to take place. The microstructure stress caused by the volume expansion of phase transformation will result in a large number of mobile dislocations in the matrix, which is beneficial to the $n$ value [29-31]. However, in the DP process, plastic strain incompatibility at the boundary between ferrite and martensite occurs, as the ferrite experiences a priority plastic deformation, and martensite has only elastic deformation. This leads to a higher value of $n$ at the initial stage of plastic deformation due to dislocation plugging entanglement in ferrite near the interface, which is caused by the incompatibility at the boundary. As the strain progresses, external forces cause the accumulated dislocations in the deformed structure to pass through the barriers resulting in plastic deformation of martensite, relaxation of the local stress concentration in the tensile deformation, and reduction of strain inconsistency between the two phases. When the strain increases to $2 \%$, the hardening effect of martensite becomes difficult to manifest and its $n$ value that was stable at about 0.07 gradually decreases to 0 .

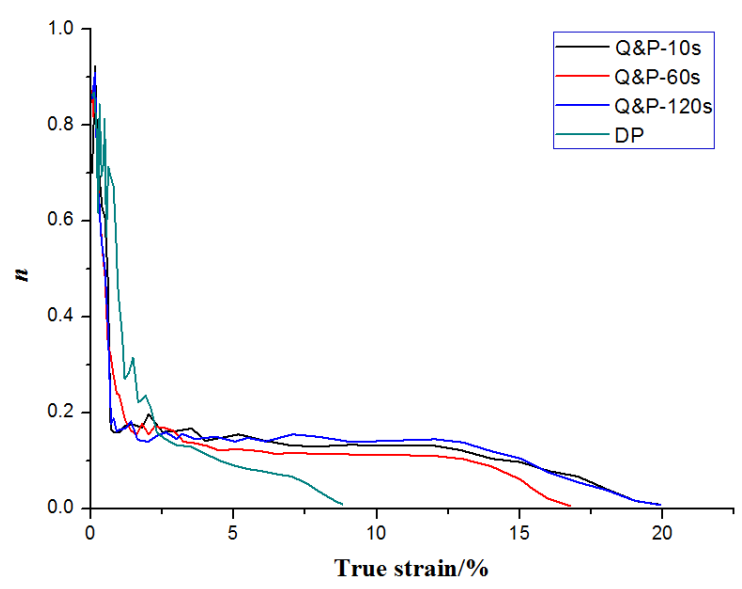

Figure 7. Relationship between $n$ value stress-strain curves of the test steel and true strain of the test steel.

The change in the $n$ value is caused by the change in microstructure. As manifested by the fine microstructure of the sample (Figure 8a), numerous fine martensite strips and thin sheets of retained austenite of width about $0.2 \mu \mathrm{m}$ were found in Q\&P steel and this effectively increased the grain boundary area between austenite and martensite. The martensitic transformation expansion resulted in the enlargement of mobile dislocation density at the interface, which in turn strengthened the interfacial impediment of dislocation movement during the deformation process. More low angle grain boundaries will increase the interfacial area, the more unfavorable it is to crack propagation and to coordinate the deformation ability of the material [32,33]. The increase of plastic strain causes the transformation of retained austenite into martensite. It can also effectively improve the strength and uniform deformation ability of the material [34,35]. In this case, the $n$ value was found to be 0.13. DP steel had more massive and elongated martensites, with a width of about $0.7 \mu \mathrm{m}$ in different orientations (Figure $8 \mathrm{~b}$ ). The width of the elongated martensite was larger than that of the samples treated by the Q\&P process. Moreover, the impact of movable dislocations produced by martensitic transformation on the $n$ value was lower leading to a relatively lower value of $n(0.07)$. Therefore, it can be concluded that the hot-rolled test steel after ultra-fast cooling and Q\&P process exhibits excellent mechanical properties. 

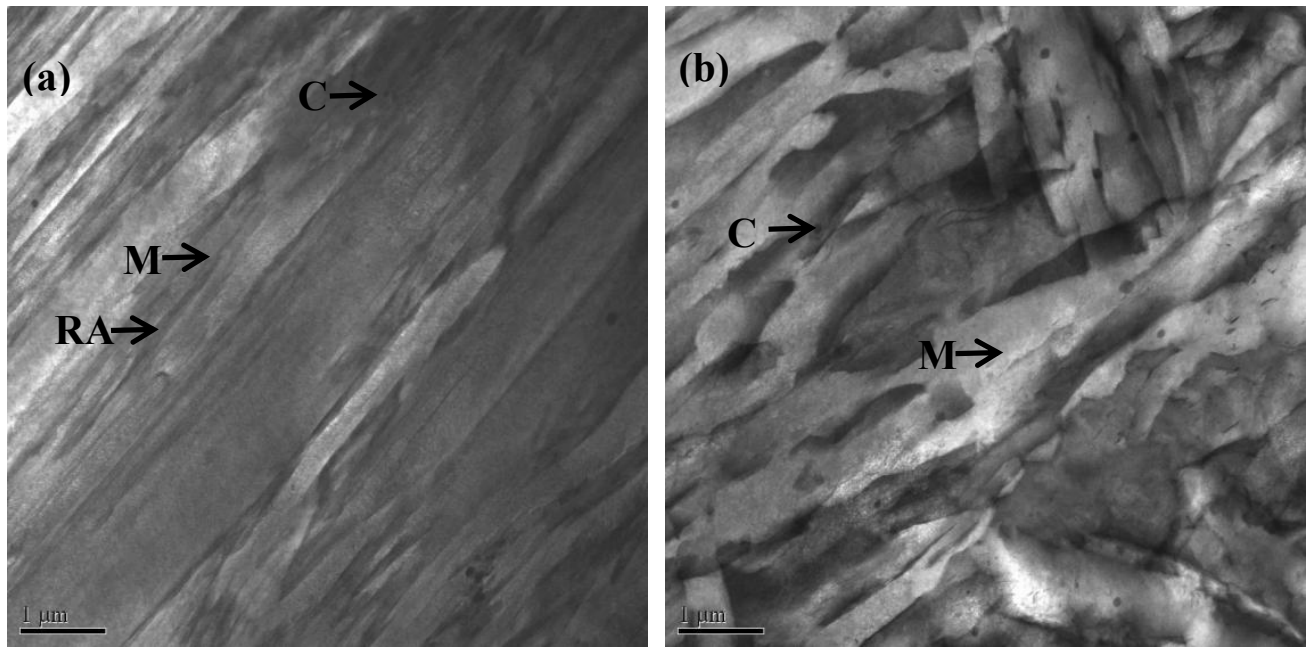

Figure 8. TEM image of the test steel with different martensite characteristics; (a) The partitioning time is $60 \mathrm{~s}$ with Q\&P processing; (b) The relaxation time is $6 \mathrm{~s}$ with DP processing. $M$ is martensite, $R A$ is retained austenite and $C$ is carbide.

\section{Conclusions}

In this work, Fe-Si-Mn- $\mathrm{Nb}$ steels containing $0.2 \mathrm{wt} \% \mathrm{C}$ were designed, then subjected to the Q\&P process and the DP process with UFC process, respectively. Higher carbon content resulted in a higher strength of hard phase-martensitic matrix and a higher volume fraction of soft phase-retained austenite.

In contrast to the traditional DP steel, refined retained austenite in hot rolled Q\&P steel prevents cracking and increases toughness, and the TRIP effect. Moreover, there are numerous fine martensite strips in the interior, which can effectively increase the grain boundary area between austenite and martensite. The martensite transformation expansion increases the mobile dislocation density at the interface, strengthens the interfacial impediment of dislocation movement in the deformation process, and effectively improves the strength and uniform deformation ability of the material.

The designed steel has the better mechanical property and formability. The highest strength-ductility of $25.359 \mathrm{GPa} \%$ together with $n$ value of 0.14 is obtained through hot rolling followed by Q\&P treatment at $350^{\circ} \mathrm{C}$ and $120 \mathrm{~s}$. This finding is crucial for the design of steels with high strength and ductility by ultra-fast cooling and Q\&P process.

Author Contributions: The author contributions have been following; T.W. and R.W. designed most of the experiments, performed most experiments, analyzed the results and wrote this manuscript. B.L., W.L., and D.K. helped hot rolled test, analyze the experiment data and gave some constructive suggestions about how to write this manuscript.

Funding: The research was supported by the National Natural Science Foundation of China (Grant No. 51771139) and Fundamental Research Funds for The State Key Laboratory of Refractories and Metallurgy (Grant No. 2018QN07).

Acknowledgments: The support of the National Natural Science Foundation of China and the State Key Laboratory of Refractories and Metallurgy for funding the research is gratefully acknowledged by the authors. Zhaojun Deng and Jun $\mathrm{Hu}$ are acknowledged for their assistance in the work.

Conflicts of Interest: The authors declare no conflict of interest. The funders had no role in the design of the study; in the collection, analyses, or interpretation of data; in the writing of the manuscript, or in the decision to publish the results.

\section{References}

1. Schmitt, J.H.; Iung, T. New developments of advanced high-strength steels for automotive applications. Comptes Rendus Phys. 2018, 19, 641-656. [CrossRef]

2. Bouaziz, O.; Zurob, H.; Huang, M. Driving force and logic of development of advanced high strength steels for automotive applications. Steel Res. Int. 2013, 84, 937-947. [CrossRef] 
3. Speer, J.G.; Matlock, D.K.; De Cooman, B.C.; Schroth, J.G. Carbon partitioning into austenite after martensite transformation. Acta Mater. 2003, 51, 2611-2622. [CrossRef]

4. Liu, H.; Lu, X.; Jin, X.; Dong, H.; Shi, J. Enhanced mechanical properties of a hot stamped advanced high-strength steel treated by quenching and partitioning process. Scr. Mater. 2011, 64, 749-752. [CrossRef]

5. Toji, Y.; Miyamoto, G.; Raabe, D. Carbon partitioning during quenching and partitioning heat treatment accompanied by carbide precipitation. Acta Mater. 2015, 86, 137-147. [CrossRef]

6. Zhang, K.; Liu, P.; Li, W.; Ma, F.; Guo, Z.; Rong, Y. Enhancement of the strength and ductility of martensitic steels by carbon. Mater. Sci. Eng. A 2018, 716, 87-91. [CrossRef]

7. Zhong, N.; Wang, X.D.; Wang, L.; Rong, Y.H. Enhancement of the mechanical properties of a Nb-microalloyed advanced high-strength steel treated by quenching-partitioning-tempering process. Mater. Sci. Eng. A 2009, 506, 111-116. [CrossRef]

8. Hou, Z.R.; Zhao, X.M.; Zhang, W.; Liu, H.L.; Yi, H.L. A medium manganese steel designed for water quenching and partitioning. Mater. Sci. Technol. 2018, 34,1-8. [CrossRef]

9. Speer, J.G.; Matlock, D.K. Developments in the quenching and partitioning process. World Iron. Steel. 2009, 9, $31-36$.

10. Tan, X.; Xu, Y.; Yang, X.; Liu, Z.; Wu, D. Effect of partitioning procedure on microstructure and mechanical properties of a hot-rolled directly quenched and partitioned steel. Mater. Sci. Eng. A 2014, 594, 149-160. [CrossRef]

11. Park, J.; Jo, M.C.; Song, T.; Kim, H.S.; Sohn, S.S.; Lee, S. Ultra-high strength and excellent ductility in multi-layer steel sheet of austenitic hadfield and martensitic hot-press-forming steels. Mater. Sci. Eng. A 2019, 759, 320-328. [CrossRef]

12. Kim, Y.W.; Song, S.W.; Seo, S.J.; Hong, S.-G.; Lee, C.S. Development of Ti and Mo micro-alloyed hot-rolled high strength sheet steel by controlling thermomechanical controlled processing schedule. Mater. Sci. Eng. A 2013, 565, 430-438. [CrossRef]

13. Cai, X.; Liu, C.B.; Liu, Z.Y. Process design and prediction of mechanical properties of dual phase steels with prepositional ultra fast cooling. Mater. Des. 2014, 53, 998-1004. [CrossRef]

14. Houyoux, C.; Herman, J.C.; Simon, P.; De Beek, M.; Riche, P. Metallurgical aspects of ultra fast cooling on a hot strip mill, Revue de Metallurgi. Revue De Metall. 1997, 97, 58-59.

15. Breedis, J. Influence of dislocation substructure on the martensitic transformation in stainless steel. Acta Metall. 1965, 13, 239-250. [CrossRef]

16. Yan, S.; Liu, X.; Liu, W.J.; Lan, H.; Wu, H. Comparison on mechanical properties and microstructure of a $\mathrm{C}-\mathrm{Mn}-\mathrm{Si}$ steel treated by quenching and partitioning (Q\&P) and quenching and tempering (Q\&T) processes. Mater. Sci. Eng. A 2015, 620, 58-66.

17. Tobata, J.; Ngo-Huynh, K.L.; Nakada, N.; Tsuchiyama, T.; Takaki, S. Role of silicon in quenching and partitioning treatment of low-carbon martensitic stainless steel. ISIJ Int. 2012, 52, 1377-1382. [CrossRef]

18. Bansal, G.; Pradeep, M.; Ghosh, C.; Rajinikanth, V.; Srivastava, V.C.; Bhagat, V.A.; Kundu, S. Evolution of Microstructure in a Low-Si Micro-alloyed Steel Processed Through One-Step Quenching and Partitioning. Metall. Mater. Trans. A 2019, 50,547-555. [CrossRef]

19. Zhang, J.; Ding, H.; Misra, R.; Wang, C. Microstructural evolution and consequent strengthening through niobium-microalloying in a low carbon quenched and partitioned steel. Mater. Sci. Eng. A 2015, 641, 242-248. [CrossRef]

20. Santofimia, M.J.; Zhao, L.; Petrov, R.; Sietsma, J. Characterization of the microstructure obtained by the quenching and partitioning process in a low-carbon steel. Mater. Charact. 2008, 59, 1758-1764. [CrossRef]

21. Santofimia, M.; Zhao, L.; Petrov, R.; Kwakernaak, C.; Sloof, W.; Sietsma, J. Microstructural development during the quenching and partitioning process in a newly designed low-carbon steel. Acta Mater. 2011, 59, 6059-6068. [CrossRef]

22. Vuorinen, E.P.; Özügürler, A.G.; Ion, J.C.; Eriksson, K.; Somani, M.C.; Karjalainen, L.P.; Allain, S.; Caballero, F.G. Hot forming of ultra-fine-grained multiphase steel products using press hardening combined with quenching and partitioning process. Metals 2019, 9, 357. [CrossRef]

23. Epp, J.; Hirsch, T.; Curfs, C. In Situ X-Ray diffraction analysis of carbon partitioning during quenching of low carbon steel. Metall. Mater. Trans. A 2012, 43, 2210-2217. [CrossRef] 
24. HajyAkbary, F.; Sietsma, J.; Miyamoto, G.; Furuhara, T.; Santofimia, M.J. Interaction of carbon partitioning, carbide precipitation and bainite formation during the Q\&P process in a low C steel. Acta Mater. 2016, 104, 72-83.

25. Huyghe, P.; Malet, L.; Caruso, M.; Georges, C.; Godet, S. On the relationship between the multiphase microstructure and the mechanical properties of a $0.2 \mathrm{C}$ quenched and partitioned steel. Mater. Sci. Eng. A 2017, 701, 254-263. [CrossRef]

26. Speer, J.G.; De Moor, E.; Findley, K.; Matlock, D.; De Cooman, B.; Edmonds, D. Analysis of microstructure evolution in quenching and partitioning automotive sheet steel. Metall. Mater. Trans. A 2011, 42, 3591-3601. [CrossRef]

27. Bagliani, E.P.; Santofimia, M.; Zhao, L.; Sietsma, J.; Anelli, E. Microstructure, tensile and toughness properties after quenching and partitioning treatments of a medium-carbon steel. Mater. Sci. Eng. A 2013, 559, 486-495. [CrossRef]

28. Cao, J.; Yan, J.; Zhang, J.; Yu, T. Effects of thermomechanical processing on microstructure and properties of bainitic work hardening steel. Mater. Sci Eng. A 2015, 639, 192-197. [CrossRef]

29. Findley, K.; Hidalgo, J.; Huizenga, R.; Santofimia, M. Controlling the work hardening of martensite to increase the strength/ductility balance in quenched and partitioned steels. Mater. Des. 2017, 117, 248-256. [CrossRef]

30. De Moor, E.; Lacroix, S.; Clarke, A.; Penning, J.; Speer, J. Effect of retained austenite stabilized via quench and partitioning on the strain hardening of martensitic steels. Metall. Mater. Trans. A 2008, 39, 2586-2595. [CrossRef]

31. Kantanen, P.; Somani, M.; Kaijalainen, A.; Haiko, O.; Porter, D.; Kömi, J. Microstructural Characterization and Mechanical Properties of Direct Quenched and Partitioned High-Aluminum and High-Silicon Steels. Metals 2019, 9, 256. [CrossRef]

32. Pozuelo, M.; Stremfel, J.W.; Yang, J.M.; Marian, J. Strengthening to softening transition in lath martensite. Materialia 2019, 5, 100254. [CrossRef]

33. Peng, F.; Xu, Y.; Li, J.; Gu, X.; Wang, X. Interaction of martensite and bainite transformations and its dependence on quenching temperature in intercritical quenching and partitioning steel. Mater. Des. 2019, 181, 107921. [CrossRef]

34. Wang, M.M.; Hell, J.C.; Tasan, C.C. Martensite size effects on damage in quenching and partitioning steels. Scr. Mater. 2017, 138, 1-5. [CrossRef]

35. He, B.B.; Hu, B.; Yen, W.H.; Cheng, G.J.; Wang, Z.K.; Luo, H.W.; Huang, M.X. High dislocation density-induced large ductility in deformed and partitioned steels. Science 2017, 357, 1029-1032. [CrossRef] [PubMed] 